\title{
Gastric Antral Diaphragm
}

\author{
Kyung J. Cho \\ Department of Radiology, University of Michigan at Wayne County General Hospital, Eloise, Michigan, U.S.A.
}

\begin{abstract}
Roentgenographic abnormalities in 3 patients with antral diaphragm are presented. Barium studies revealed the diaphragm as a persistent, circumferential defect in the distal antrum, often associated with peptic ulcers or gastric outlet obstruction. At endoscopy the central aperture does not change during peristalsis in contrast to the pylorus, which does. Since the lesion can be excised, its preoperative demonstration by barium studies and endoscopy is emphasized.
\end{abstract}

Key words: Stomach - Diaphragm - Diagnosis Endoscopy.

The antral mucosal diaphragm, a circumferential membrane of mucosa and submucosa, often causes some degree of gastric outlet obstruction. In 1949 Sames [1] first described this rare entity. Since then 52 patients have been reported (2-25]. In 3 patients, examined at University Hospital and Wayne County General Hospital, an antral mucosal diaphragm was diagnosed by barium examination and confirmed by gastroscopy.

\section{Case Reports}

Case 1. A 50-year-old woman had a 5-year history of indigestion and epigastric fullness after meals. Two upper gastrointestinal examinations a year apart demonstrated a persistent circumferential defect about $1 \mathrm{~cm}$ proximal to the pylorus, perpendicular to the longitudinal axis of the antrum (Fig. 1). The diameter of the aperture was $6.0 \mathrm{~mm}$. A small ulcer was present immediately distal to the diaphragm. Gastroscopy confirmed that the lesion was a persistent mucosal membrane with areas of erosion and erythema. The contour of the aperture did not change during peristalsis.

Case 2. A 57-year-old man had been followed because of hypertension and anemia. Physical examination and past history were

Address for reprint requests: Kyung J. Cho, M.D., Department of Radiology, University of Michigan at Wayne County General Hospital, Eloise, MI 48132, U.S.A. unremarkable. An upper gastrointestinal examination demonstrated a persistent radiolucent circumferential defect in the prepyloric antrum $3 \mathrm{~cm}$ proximal to the pylorus with an aperture $1.2 \mathrm{~cm}$ in diameter. A mucosal polyp was present immediately distal to the diaphragm (Fig. 2). Gastroscopy showed a circular elevated mucosa and a polyp distal to an antral diaphragm (Fig. 3). The biopsy showed chronic gastritis.

Case 3. A 55-year old woman was admitted because of recent onset of a seizure disorder and hematemesis. Two months previously gastroscopy showed a small pyloric opening and gastric ulcer. Upper gastrointestinal examination revealed a severe gastric outlet obstruction. With compression, the mucosal diaphragm was seen as a persistent defect $1.6 \mathrm{~cm}$ proximal to the pylorus. The aperture was $3.0 \mathrm{~mm}$ in diameter (Fig. 4). Endoscopy confirmed the diaphragm with a small aperture, which did not change during active peristalsis. The mucosa was erythematous with areas of superficial erosion. The diaphragm was excised through a gastrostomy. Histologic section of the diaphragm showed a normal gastric mucosa, with submucosa and muscularis mucosae, associated with chronic gastritis (Fig. 5). The patient's symptoms subsequently improved. Repeat barium study month later showed a postsurgical change.

\section{Discussion}

The antral diaphragm is a rare but well-known gastric lesion, usually discovered in middle or late life because of associated gastric outlet obstruction or peptic ulcers. As noted by Gerber [8] and Cremin [6], the lesion also occurs in infants and children. Recently, Ghahremani [9] reported 6 cases of nonobstructing mucosal antral diaphragm in adults.

Of the 52 cases reported in the literature, the age at diagnosis ranges from 28 to 84 years, averaging 54.8 years. There are 30 females and 22 males, a ratio of $1.36: 1$.

The etiology of antral diaphragm is not yet clear. Both congenital and acquired origins have been proposed. The congenital theory is based on the entity described in infants and the absence of an inflammatory reaction, and suggests a failure in embryonic recanalization of the antrum as the possible etiology 

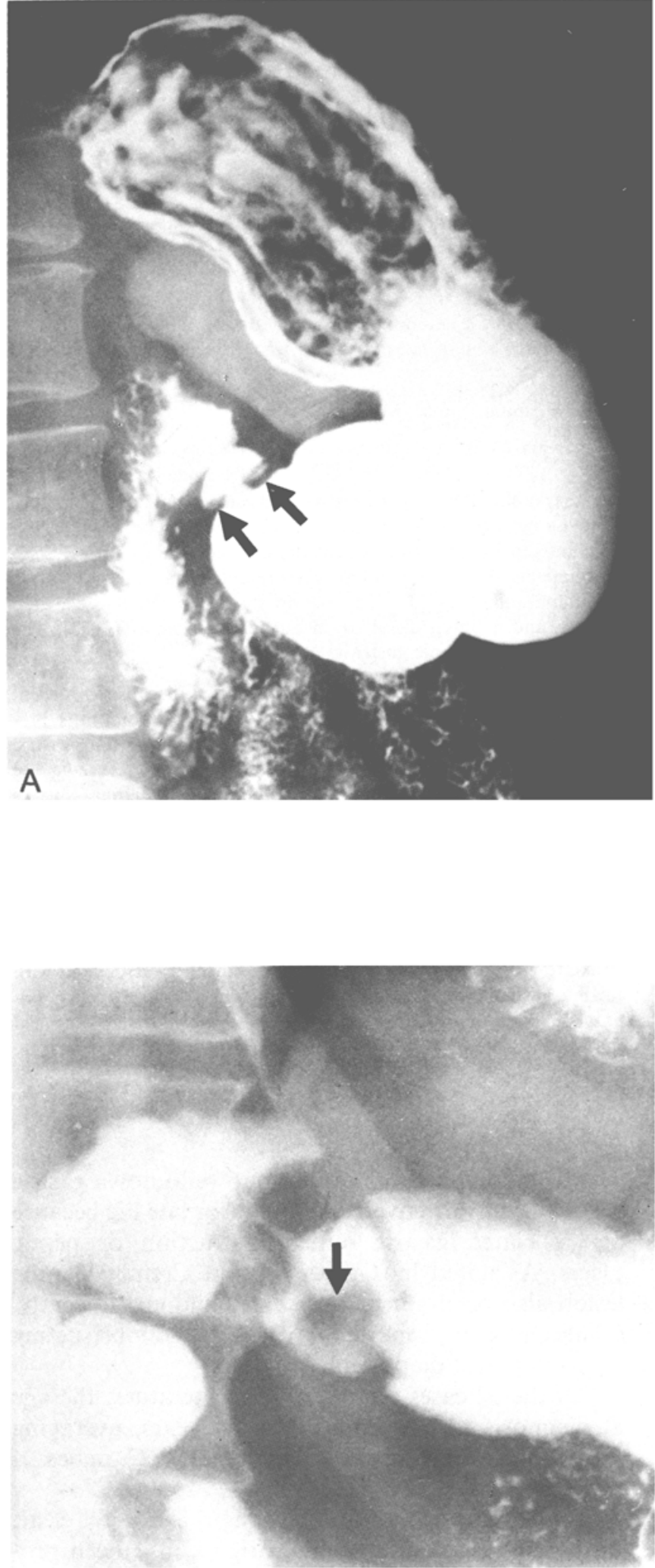

Fig. 2 (Case 2). A smooth, crescentic, radiolucent defect is present in the prepyloric antrum $3 \mathrm{~cm}$ proximal to the pylorus. A mucosal polyp is noted immediately distal to the antral diaphragm (arrow)

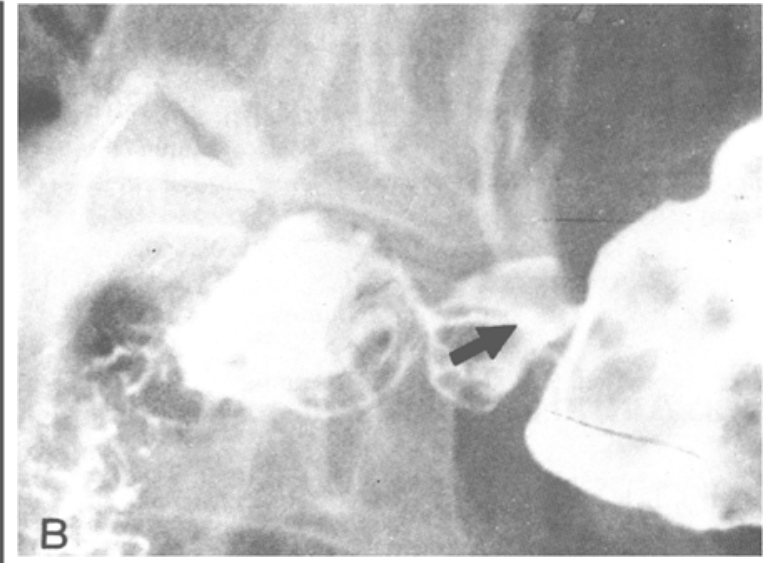

Fig. 1 (Case 1).

A A symmetric, sharp defect about $1 \mathrm{~cm}$ proximal to the pylorus (arrows) represents a mucosal diaphragm. B An air contrast study reveals a small ulcer crater immediately distal to the diaphragm (arrow)

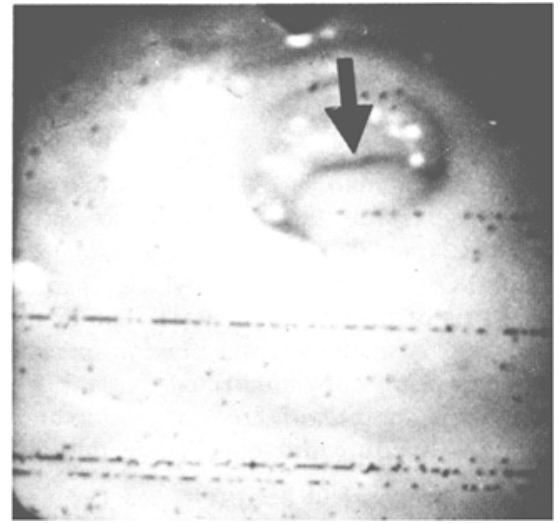

Fig. 3 (Case 2). Gastroscopy shows a circular, smooth, elevated mucosa. The contour of the diaphragm did not change during peristalsis. A polyp is shown partially obscuring the pylorus (arrow) 


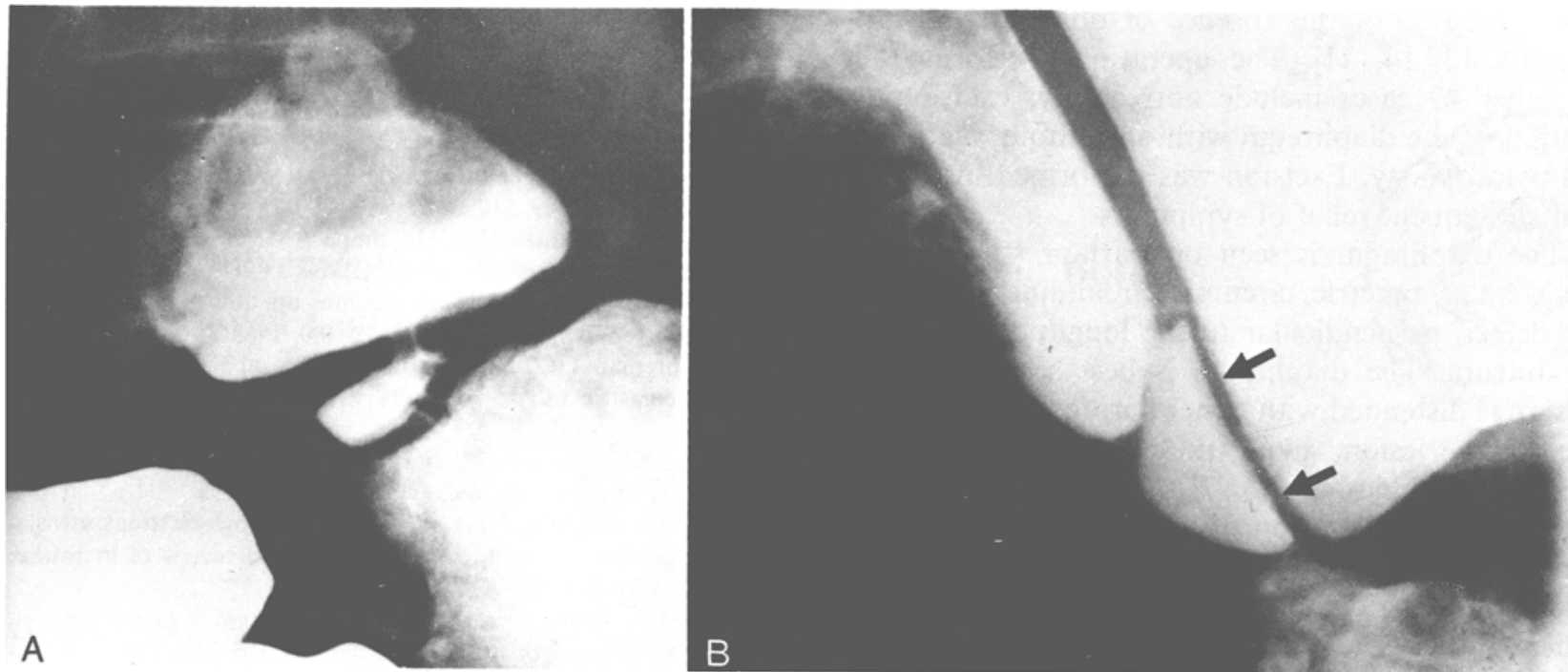

Fig. 4 (Case 3). A With compression the antral diaphragm is demonstrated, causing a persistent defect in the prepyloric antrum. B The portion of the antrum between the pylorus and diaphragm (arrows) is distended, showing a double-bulb appearance

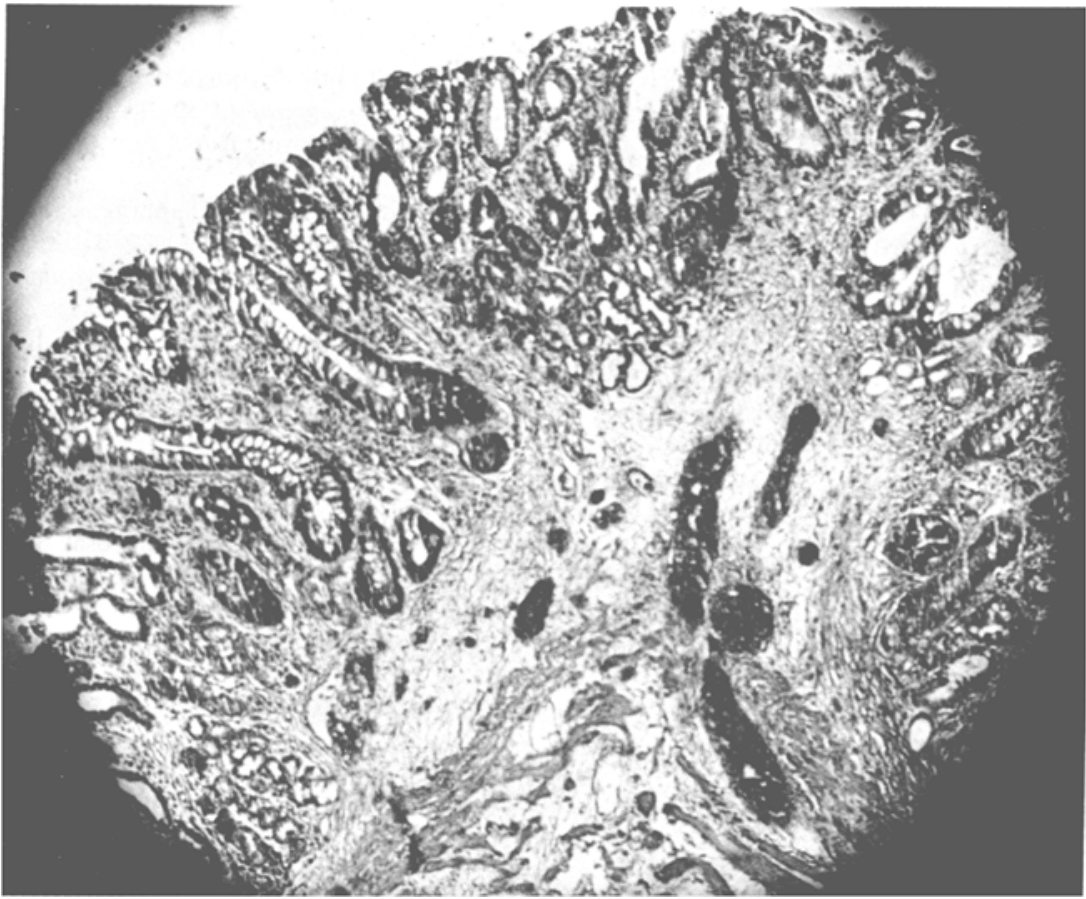

Fig. 5 (Case 3). Photomicrograph of the excised mucosal diaphragm shows normal gastric mucosa, submucosa and muscularis mucosae, associated with nonspecific inflammation
$[6,11,12]$. The acquired theory is supported by a higher incidence of the diaphragms in adults, possibly secondary to a healing ulcer $[9,17]$.

The diaphragm may occur anywhere along the antrum, from the pylorus to $7 \mathrm{~cm}$ proximal to the pylorus $[3,7,11,17,18,24]$. Its thickness is usually 2 to $3 \mathrm{~mm}$. A diaphragm with an aperture of over $1.0 \mathrm{~cm}$ generally does not cause obstruction and does not require surgery [9].
The diaphragm is composed of two surfaces of mucosa with a common submucosa and muscularis mucosae. Chronic inflammatory reactions have been reported in some patients $[7,24]$. Histologic examination of cases 2 and 3 showed chronic gastritis.

Most patients have upper gastrointestinal symptoms, such as epigastric pain and fullness after a heavy meal, and nausea and vomiting. Surgery was not performed in 9 of the 52 previously reported cases, pri- 
marily because of the absence of obstructive symptoms $[9,12,14,21]$. The operations performed in the other 43 cases include antrectomy, excision or incision of the diaphragm with or without vagotomy and pyloroplasty. Excision was performed in case 3, with subsequent relief of symptoms.

The diaphragm is seen on barium studies as a persistent, symmetric, circumferential, linear or bandlike defect, perpendicular to the longitudinal axis of the antrum. The diaphragm is best seen when the antrum is distended with either barium or air on both sides of the lesion, giving the characteristic appearance of a double-bulb [3, 7]. An air contrast study following administration of an anticholinergic agent can enhance delineation of the diaphragm [9]. The pylorus must be demonstrated in a highly obstructed patient; otherwise, an antral diaphragm can be mistaken for pyloric obstruction. Indeed, a correct diagnosis was not made in case 3 until the pylorus was seen at the second examination.

At endoscopy the lesion appears as a persistent circular elevation of normal mucosa. The central aperture does not change during peristalsis, in contrast to the pylorus which intermittently opens and closes. Although the mucosa of the diaphragm has been normal in most of the previous cases, erosion and erythema of the antral mucosa were observed in these 3 patients. About one-fourth of the reported cases have had either gastric or duodenal ulcers.

Since surgical excision of the antral diaphragm can cure the patient's symptoms, a correct diagnosis by both upper gastrointestinal examination and endoscopy is important.

\section{References}

1. Sames CP: A case of partial atresia of the pyloric antrum due to a mucosal diaphragm of doubtful origin. $\mathrm{Br} J$ Surg $37: 244.246,1949$

2. Albot G, Magnier F: Mucosal diaphragm of pyloric antrum Arch Mal Appar Dig 44:1162-1166, 1955

3. Banks PA, Waye JD, Waitman AM, et al: Mucosal diaphragm of gastric antrum. Gastroenterology 52:1003-1008, 1967

4. Browning $\mathrm{RW}$ : Prepyloric antral mucosal diaphragm or "Web." Am Surg 30:73-76, 1964

5. Conway $\mathrm{N}$ : Pyloric antral mucosal diaphragm. $\mathrm{Br} \mathrm{Med} J$ 1:970-971, 1965

6. Cremin BJ: Congenital pyloric antral membranes in infancy. Radiology 92:509-512, 1969

7. Felson B, Berkmen YM, Hoyumpa AM: Gastric mucosal diaphragm. Radiology 92:513-517, 1969

8. Gerber BC: Prepyloric diaphragm, an unusual abnormality. A case report. Arch Surg 90:472-480, 1965

9. Ghahremani GG: Nonobstructive mucosal diaphragms or rings of the gastric antrum in adults. Am J Roentgenol 121:236-247, 1974

10. Gross KE, Durham MW: Pyloric antral mucosal diaphragm: Report of a case. Radiology 61:368-372, 1953

11. Hait G, Esselstyn CB, Rankin GB: Prepyloric mucosal diaphragm (antral web). Report of case and review of literature. Arch Surg 105:486-490, 1972

12. Katz LA : Asymptomatic mucosal diaphragm of gastric antrum Report of case. Gastrointest Endosc 15:106-107, 1968

13. Kenny PJ: The adult pyloric diaphragm. Aust $N Z \cdot J$ Surg $32: 270-273,1962$

14. Melamed A, Haukohl RS, Callan RE: Pyloric antral mucosal diaphragm with transpyloric mucosal prolapse. Radiology $74: 452-457,1960$

15. Munro AI : Prepyloric mucosal diaphragm. Br J Surg 50:981982, 1963

16. Pulsifer L, Jedd FL, VanZandt TF: Pyloric obstruction by a mucosal diaphragm. Am J Gastroenterol 43:30-34. 1965

17. Rhind JA: Mucosal stenosis of the pylorus. Brit $J$ Surg $46: 534$ 540,1959

18. Rota AN: Pyloric obstruction due to mucosal diaphragm. Arch Pathol 55:223-226, 1953

19. Rowling JT: The prepyloric septum: A rare anomaly. $\mathrm{Br} J$ Surg 47:162-166, 1959

20. Schwartz IR, Hirsch E, Mule JE et al: Antral mucosal diaphragm: Clinical and roentgen characteristics, with first reported case of vibrio fetus in human bile. Am J Gastroenterol 45:366373, 1966

21. Sokol EM, Shorofsky MA, Werther JL: Mucosal diaphragm of gastric antrum. Bull Gastrointest Endosc 12:20-21, 1965

22. Spencer SL: Adult pyloric obstruction due to a mucosal diaphragm. Med $J$ Aust 48:816-817, 1961

23. Stahl WM Jr: Unusual pyloric obstruction in an adult: Congenital partial diaphragm of pylorus. JAMA 186:1173--1175. 1963

24. Swartz WT, Shepard RD: Congenital mucosal diaphragm of pyloric antrum. J Kentucky Med Assoc 54:149-151, 1956

25. Young HB: Addisonian pigmentation due to extreme pyloric stenosis by a mucosal diaphragm. Br J Surg 49:104-107, 1961 